\title{
SCAFOLDING DALAM MENYELESAIKAN SOAL EKSPONEN MAHASISWA DITINJAU DARI TEORI BRODIE
}

\author{
${ }^{1}$ Fhela Vhantoria Ningrum \\ 1riavhantoria@gmail.com
}

\section{Universitas Muhammadiyah Kotabumi}

\begin{abstract}
The purpose of describing scaffolding in solving student exponential problems in terms of Brodie's theory. Qualitative descriptive method. Data were collected using tests and interviews with first-semester students of the Mathematics Study Program, University of Muhammadiyah Kotabumi. Research subjects 4 of 28 students of mathematics education study program. In classifying the types of errors using Brodie's theory, namely 1) basic error, 2) appropriate error, 3) missing information, and 4) partial insight. Then the way to overcome student errors is given by scaffolding based on Anghileri's theory, namely environmental provisions, (explaining, reviewing, and restructuring), and developing conceptual thinking. The results of study 1) students' errors in solving exponential questions on basic errors, namely misunderstanding the questions, 2) meaningful learning helps students to better understand the questions, 3) scaffolding is carried out based on the three levels of Anghileri scaffolding, and 4) scaffolding is given in the form of directives so that students better understand the problem.
\end{abstract}

Keywords: Student Error, Exponent, Brodie, Scaffolding

\begin{abstract}
Abstrak: Tujuan mendiskripsikan scafolding dalam dalam menyelesaikan soal eksponen mahasiswa ditinjau dari teori brodie. Metode deskriptif kualitatif. Data dikumpulkan dengan cara tes dan wawancara mahasiswa semester 1 Prodi Matematika Universitas Muhammadiyah Kotabumi. Subjek penelitian 4 dari 28 mahasiswa program studi pendidikan matematika. Dalam mengelompokkan tipe kesalahan menggunakan teori Brodie yaitu 1) basic error, 2) appropriate error, 3) missing information, and 4) partial insight. Kemudian cara mengatasi kesalahan mahasiswa diberi scafolding berdasarkan teori Anghileri yaitu environmental provisions, (explaining, reviewing, and restructuring), and develoving conceptual thinking. Hasil penelitian 1) kesalahan mahasiswa dalam menyelesaian soal eksponen pada basic error yaitu kesalahan memahami soal, 2) Pembelajaran yang bermakna membantu mahasiswa untuk lebih memahami soal, 3) scafolding dilakukan berdasarkan ketiga level scafolding Anghileri, dan 4) scafolding yang diberikan berupa petunjuk arahan agar mahasiswa lebih memahmi soal.
\end{abstract}

Kata Kunci: Kesalahan Mahasiswa, Eksponen, Brodie, Scafolding

\section{PENDAHULUAN}

Eksponen merupakan salah satu cakupan materi pada mata kuliah aljabar di program studi pendidikan matematika
Universitas Muhammadiyah Kotabumi. Mata kuliah ini diampu mahasiswa pada semester satu sebagai mata kuliah aljabar yang dengan kata lain adalah Kalkulus dasar. Ruang lingkup materi berupa materi yang 
sebagian besar telah dipelajari di bangku Sekolah Menengah Atas. Meskipun telah dipelajari, namun kesalahan mahasiswa dalam menyelesaikan soal tetap terjadi khususnya ekponen. Sehingga perlu adanya penanganan terkait kesalahan agar tidak terjadi kembali.

Berikut kategori kesalahan mahasiswa dalam matematika yang disimpulkan dari beberapa penelitian yang lingkupnya analisis kesalahan mahasiswa dalam menyelesaikan soal matematika: 1) kesalahan konsep, 2) kesalahan interpretasi bahasa, 3) kesalahan perhitungan, 4) kesalahan data, dan 5) hasil akhir tidak diperiksa kembali (Ratih Hendrastuti, 2019). Banyak macam teori dalam menganalisis kesalahan, dalam penelitian ini teori yang dipakai menurut Brodie. Brodie mempunyai 4 tipe kesalahan dalam menyelesaikan soal matematika khususnya dalam hal ini eksponen. Setelah mengkategorikan tipe kesalahan maka dosen merancang scafolding yang akan diberikan pada mahasiswa sebagai bantuan.

Cara dosen mengatasi kesalahan mahasiswa dalam pembelajaran adalah dengan memberikan bantuan yaitu scafolding. Anghileri dalam (Rahayu, Warli, \& Cintamulya, 2020), Scafolding selalu disesuaikan dengan kebutuhan mahasiswa. Penelitian (Yulius Tyaningsih, Novitasari, Hamdani, Dwi Handayani, \& Samijo, 2020) mengatakan bahwa scafolding akan berhasil jika subjek memiliki kemauan untuk memperbaiki kesalahan.

Berdasarkan uraian di atas maka peneliti ingin melakukan penelitian terkait scafolding dalam menyelesaikan soal eksponen mahasiswa ditinjau dari teori brodie

\section{METODE}

Kualitatif deskriptif dipilih sebagai metode dalam penelitian ini. Tujuan mendiskripsikan scafolding dalam dalam menyelesaikan soal eksponen mahasiswa ditinjau dari teori Brodie. Data dikumpulkan dengan cara tes dan wawancara mahasiswa semester 1 Prodi Matematika Universitas Muhammadiyah Kotabumi. Subjek penelitian adalah 4 orang dari 28 mahasiswa dalam satu kelas. Subjek penelitian dipilih berdasarkan hasil jawaban tes diagnostik. Berikut langkah hasil jawaban mahasiswa: 1) desktipdi tipe kesalahan, dan 2) Hasil tes mahasiswa dalam menyelesaikan soal ekponen dianalisis menggunakan teori Brodie. Kesalahan. Empat kesalahan menurut Brodie: 1) basic error, 2)appropriate error, 3) missing information, and 4) partial insight (Nurul Syariah \& Haerudin, 2021)

Kemudian scafolding dirancang sesuai dengan hasil tes mahasiswa menggunakan 
teori scafolding Anghileri. Berikut tiga level scafolding : environmental provisions, (explaining, reviewing, and restructuring), develoving conceptual thinking (Hasan, 2020).

Tabel 1. Soal tes diagnostik

\section{Soal}

Diketahui $2^{x}+2^{-x}=5$. Nilai $2^{2 x}+$ $2^{-2 x} ?$

\section{HASIL DAN PEMBAHASAN}

Hasil

Berikut ini kesalahan dalam menyelesaikan soal eksponen dan penyebabnya dapat dilihat pada gambar 1-4.

$$
\text { 2. } \begin{aligned}
& 2^{x}+2^{-x}=5 \\
& 2^{2 x}+2^{-2 x} \\
= & 2^{x}+2^{2}+2^{-x}+2^{2} \\
= & 2^{x}+2^{-x}+2^{2}+2^{2} \\
= & 5+4+4 \\
= & 13
\end{aligned}
$$

Gambar 1. Kesalahan Subjek 1 menggunakan sifat-sifat eksponen

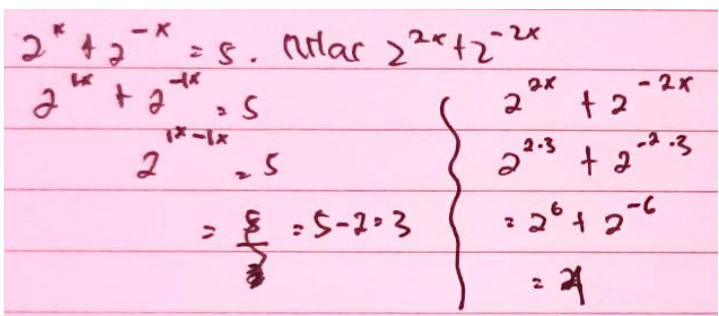

Gambar 2. Kesalahan Subjek 2 menggunakan Sifat-sifat eskponen

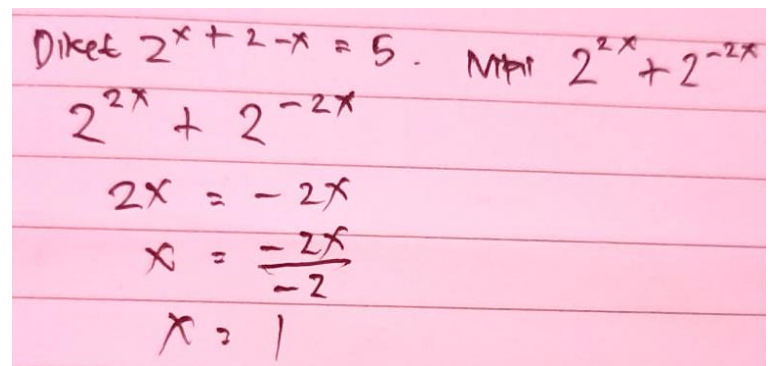

Gambar 3. Kesalahan Subjek 3 menggunakan bentuk persamaan eksponen.

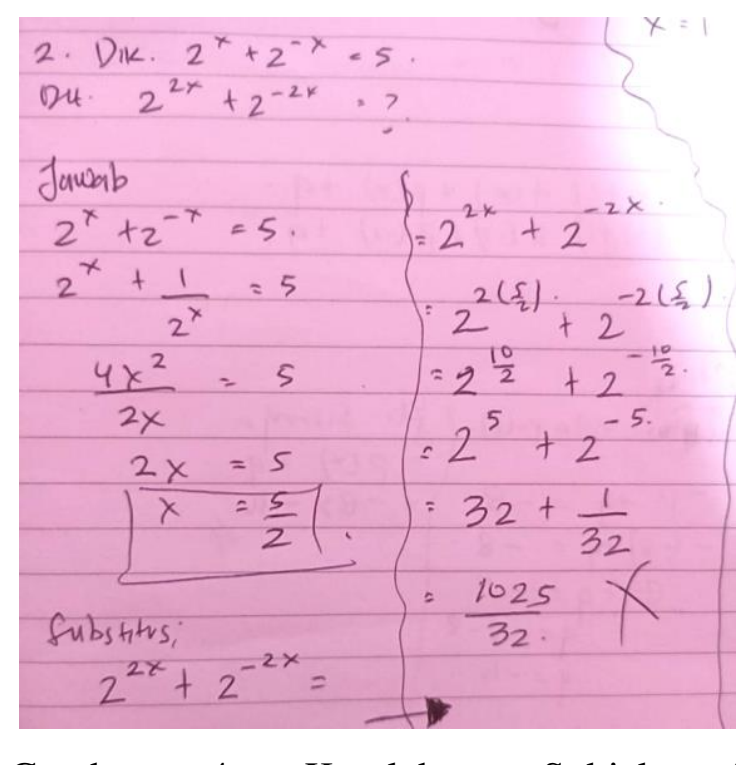

Gambar 4. Kesalahan Subjek 4 menggunakan penyederhanaan ekponen.

Setelah kesalahan dan penyebabnya maka dirancang scafolding untuk mengatasinya. Uraian scafolding ditinjau dari pendapat brodie terdapat pada pembahasan.

\section{Pembahasan}

Subjek 1 (S1) dalam menyelesaikan tes diagnostik dengan cara $a^{m n}=a^{m}+a^{n} \cdot S 1$ beranggapan cara tersebut berdasarkan sifat eksponen $\mathrm{a}^{\mathrm{m}} \mathrm{x} \mathrm{a}^{\mathrm{n}}=\mathrm{a}^{\mathrm{m}+\mathrm{n}}$. Kemudian Subjek 2 (S2) dalam menyelesaikan tes diagnostik dengan cara $a^{m}+a^{n}=a^{m+n} . S 2$ beranggapan cara tersebut berdasarkan sifat eksponen $\mathrm{a}^{\mathrm{m}}$ 
$\mathrm{x} \mathrm{a}^{\mathrm{n}}=\mathrm{a}^{\mathrm{m}+\mathrm{n}}$. Selanjutnya Subjek $3(\mathrm{~S} 3)$ dalam menyelesaikan tes diagnostik menggunakan bentuk persamaan eksponen $\mathrm{a}^{\mathrm{f}(\mathrm{x})}=\mathrm{a}^{\mathrm{g}(\mathrm{x})}$ karena memiliki basis yang sama maka $\mathrm{f}(\mathrm{x})$ $=\mathrm{g}(\mathrm{x})$. Terakhir Subjek 4 (S4) dalam menyelesaikan test diagnostik dengan menyederhanakan eksponen. S4 menyamakan penyebut untuk mendapatkan nilai $\mathrm{x}$ yang kemudian disubstitusikan dalam persamaan yang menjadi soal.

Seluruh subjek kembali melakukan kesalahan yang sama yaitu ketika terperangkap dan tidak menemukan alur penyelesaian yang sesuai maka tidak mencoba untuk menggunakan cara lain. Dalam penyelesaian tes diagnostik yang benar dengan menguadratkan kedua ruas $2^{\mathrm{x}}+2^{-\mathrm{x}}=5$. Kemudian jabarkan kuadrat ruas kiri $(a+b)^{2}=(a+b)(a+b)$. Berdasarkan teori Brodie kesalahan yang dilakukan semua subjek termasuk dalam kesalahan memahami soal atau basic error.

Dikatakan kesalahan memahami soal karena pembelajaran kurang bermakna. Hal tersebut dilihat dari mahasiswa belum mampu memahami soal kemudian menghubungkan konsep baru dengan konsep yang telah dimiliki sebelumnya. pembelajaran akan bermakna apabila subjek secara totalitas memahami objek pembelajaran, menghubungkan antara unsur, dan menghubungkan pengetahuan satu dengan lainnya (Sutarto, 2017). Didukung dengan penelitian (Wahyuni \& Nurhadi,
2018) bahwa tipe kesalahan basic error karena pembelajaran kurang bermakna sehingga subjek tidak mampu memahami soal khusunya kesalahan memahmi konsep.

Keempat subjek memiliki tipe kesalahan yang sama yaitu basic error atau kesalahan memahami soal Berdasarkan tipe kesalahan basic error maka scafolding Anghileri dalam yang diberikan adalah sebagai berikut: level 1 environmental provisions yaitu dengan memberikan tugas terstruktur. Subjek diminta menuliskan ulang jawaban tes diagnostik. Kemudian dilanjutkan level 2 explaining, reviewing, dan restructuring yaitu dosen meminta mahasiswa mengulas kembali cara yang digunakan sudah sesuai atau belum berdasarkan sifat dan bentuk eksponen yang telah dipilih. Level 3 develoving conceptual thinking dimana dosen meminta mahasiswa memikirkan cara diluar dari sifat-sifat dan bentuk eksponen yang telah mereka pelajari. Pada saat subjek melakukan kesalahan memahami soal maka scafolding yang tepat berupa pertanyaan arahan untuk memahami soal (Prayitno, 2017).

\section{SIMPULAN}

Berdasarkan hasil dan pembahasan maka disimpulkan 1) kesalahan mahasiswa dalam menyelesaian soal eksponen pada basic error yaitu kesalahan memahami soal, 
2) Pembelajaran yang bermakna membantu mahasiswa untuk lebih memahami soal, 3) scafolding dilakukan berdasarkan ketiga level scafolding Anghileri, dan 4) scafolding yang diberikan berupa petunjuk arahan agar mahasiswa lebih memahmi soal.

\section{DAFTAR PUSTAKA}

Hasan, B. (2020). kesulitan Siswa dan Scafolding Dalam Menyelsaikan Masalah Geometri Ruang. Jurnal Numeracy, 7(1), 49-64.

Nurul Syariah, R., \& Haerudin. (2021). Analisis Kesalahan Siswa Dalam Mengerjakan Soal Eksponen Ditinjau Dari Teori Broide. MAJU: JURNAL ILMIAH PENDIDIKAN MATEMATIKA, 8(2), 348-353.

Prayitno. (2017). Karakterisasi Scafolding Berdasarkan Kesalahan Berpikir Siswa Dalam Menyelesaikan Masalah Matematika. Jurnal Kependidikan, Penelitian Inovasi Pembelajaran, 1(1), 50-67. https://doi.org/https://doi.org/10.21831/jk.v1i1.10059

Rahayu, P., Warli, \& Cintamulya, I. (2020). Scafolding Dalam Pembelajaran Mata Kuliah Struktur Aljabar. Jurnal Ilmiah Pendidikan Matematika, 5(1), 25-35. Retrieved from http://journal.upgris.ac.id/index.php/JIPMat/article/view/4838/pdf

Ratih Hendrastuti, Z. (2019). Analisis Kesalahan Mahasiswa Program Studi Pendidikan Matematika Ditinjau Dari Hasil Belajar Mahasiswa Mata Kuliah Aljabar. ProsidingPM37, 1-10. Retrieved from https://publikasiilmiah.ums.ac.id/bitstream/handle/11617/11056/PM37.pdf?sequence=1

Sutarto. (2017). Teori Kognitif dan Implikasinya Dalam Pembelajaran. Jurnal Bimbingan Dan Konseling Islam, 1(2), 1-26. https://doi.org/http://dx.doi.org/10.29240/jbk.v1i2.331.

Wahyuni, R., \& Nurhadi, D. (2018). Tipe-tipe Kesalahan Siswa Dalam Meyelsaikan Soal Pada Aturan Eksponen Dan Scafoldingnya Studi Kasus Di SMKN 11 Malang. Teknologi Dan Kejuruan, $\quad 41(2), \quad 173-186$. https://doi.org/http://dx.doi.org/10.17977/um031v41i22018p173

Yulius Tyaningsih, R., Novitasari, D., Hamdani, D., Dwi Handayani, A., \& Samijo. (2020). Pemberian Scafolding Terhadap Berpikir Pseduo Penalaran Siswa Dalam Mengkonstruksi Grafik Fungsi. JSE, 1(1), 20-31. Retrieved from https://jse.rezkimedia.org/index.php/jse/article/view/9 